\title{
A Flash-Based Game for Employee Doing On-the-Job Training
}

\author{
Eduardo Werneck and Maiga Chang \\ School of Computing and Information Systems, Athabasca University, Canada \\ eduardo_d_werneck@yahoo.com, maiga@ms2.hinet.net
}

\begin{abstract}
Educational games have been widely developed and tested by many researchers. Most of results show that the educational games are good to increase student's learning motivation in formal learning. It seems quite workable, however, what kinds of game-based learning a business really want to see and want to use? This research reveals the project of designing and implementing a game-based learning system within a real corporate environment. After been through the tough process of finding a company willing to adopt the game for its on-the-job training and orientation as well as the negotiations, the legal issues and the extensive scrutiny, it's amazing to find that what a real world company asks for is such a small and simple game. The game has been approved by the officer and ready to provide to phone and face-to-face sales who have no minimum necessary knowledge of selling watercrafts insurance and have interest in using game-based learning mode instead of PowerPoint presentation mode. The officer mentioned that he was quite happy with the game.
\end{abstract}

Keywords: game-learning learning, training, joy, computer game, educational games.

\section{Introduction}

Some researchers point out that playing can hold student attentions and make learning be more interesting [2][10]. For this reason, many studies use commercial games directly or design new education games and have evidences of students can get significant improvement in learning [1][6][8][10].

Several studies have been carried out on game-based learning with an educational orientation, especially for a possible use in either helping learning the traditional classroom environment, or supporting teaching activities [4], with improving techniques like the multi level challenge system [3]. Other game-based learning systems were, for examples, VISOLE [5], AnswerMatching [12], Shadow Box [7], and Simulation Fish Tank [9].

This paper describes a Flash-based On-the-Job Training game for teaching a mix of phone sales and face-to-face sales in R-Company boating regulation and insurance policy. This paper is organized into three sections, Section 2 talks the game itself and Section 3 reveals the evaluation plan. 


\section{The Game}

The process of recruiting a company willing to allow its employees to participate in an academic empiric research is not an easy task, when the subject of the study is Game-Learning. Armed with a mini-proposal and a sales plan explaining the benefits for an organization to help out with an academic study was not enough [11]. The word game represents a major road blocker, even after carefully explaining factual information regarding peer review studies showing game-learning systems as a powerful and effective learning tool.

The initial prototype was quite different from the final version of the game, basically due to the several changes initiated by the company. The involved employees take the project as something produced by their own department, and not an academic project. It was quite usual to receive a request to modify something related to the game, and not the training content itself [11].

This rest of this section describes the game and its mechanics, showing the details of how to play it and visually explaining all the steps of the tool.

The idea was to have a presentation style training embedded in a board game. In order to cut production and development time, the game was developed in Flash CS3, using ActionScript 2 in an Apple Macbook Pro $2.5 \mathrm{GHz}$ with 4 GB memory. A prototype was initially designed and sent to the Learning and Development team of RCompany and evolved in the final game shown below. Without going into details, a brief description of the game mechanics is described below.

Figure 1 shows the screenshot of the game, with the presentation panel at the top left hand side with the pagination on the top right of the frame, the company logo at the top, the path for the sailing boat in dash style at the right hand side, plotted around the island, with pirate flags as part of the path. There is a start and finish lines, as in a boat race, at the bottom of the screen and the sailing boat parked at the start line. The finish line is a treasure "x". The green die with the button roll is at the bottom left hand side and right beside, on the right, is the points panel, with the 2 shark fins beside it. The shark fins are used to navigate through the presentation panel (back and forward).

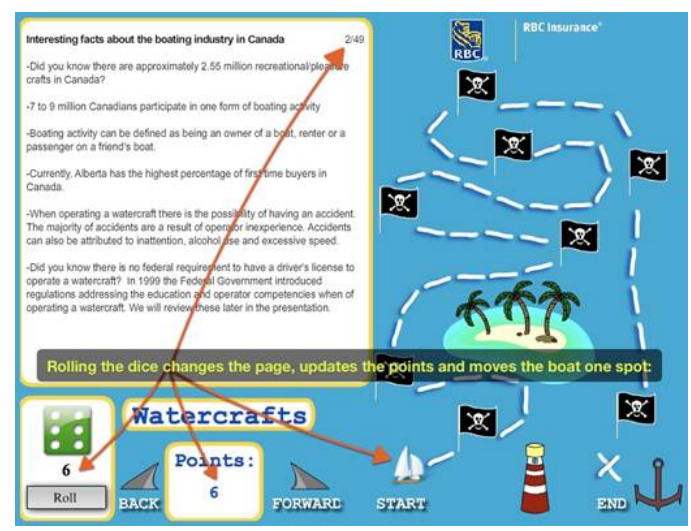

Fig. 1. Game Mechanics - how to move through the game 
In order to start playing, the employee has to click in the button named roll, which will roll the dice, giving a number from 1 to 6 . This number is going to update the points box, advance one chart in the presentation panel and no matter what number the employee rolled out, the sailing boat moves one spot (or dash) at a time. The points the employee receives at the end of the game currently is only for fun and s/he may compete with each others to see who has better lucky. There is "win" situation, but there is a scoring through points, so the objective of the game itself is to score as much points, as possible.

In order to bring up excitement, a challenging situation was created through the pirate flags: every time the boat moves to one of these 8 flags, the presentation panel will bring up a quiz, which has to be answered by clicking in the true, or false button: without selecting an answer, the game does not go on and the sailing boat will be stationary in the current position, with the roll button deactivated, as seen in Figure 2. The questions used in this quiz are exactly the same used for the pre-test, however, they were positioned after the corresponded charts teaching the respective subject. The use of the quiz was supposed to help with the engagement, at the same time as it would help in understanding the lessons and improving the learning process.

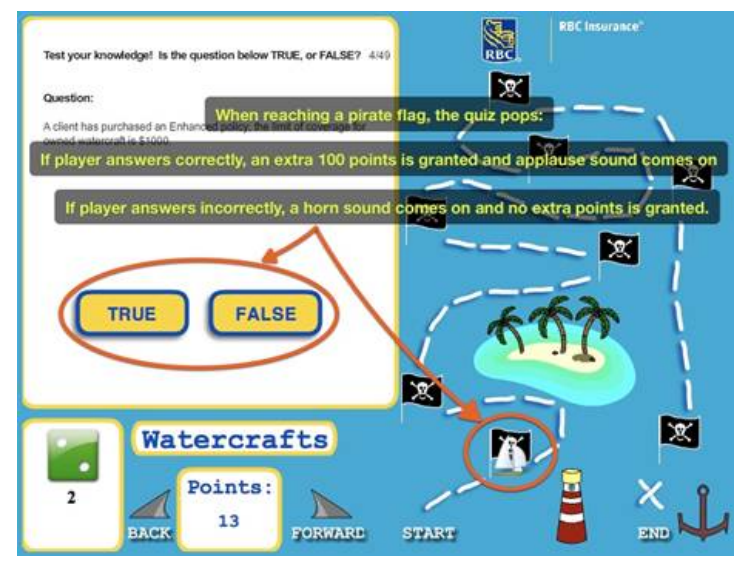

Fig. 2. The Quiz Process

The game will end when the boat reaches the "x", coinciding with the last presentation chart, which is number 49. At this moment, a voice saying "job well done" will play, the presentation chart in the presentation panel will inform the player about the end of the training and ask them to either play the game again, or to go to their posttest questions posted at the training portal.

\section{Evaluation Plan}

The evaluation process starts with the pre-test of employees who need to have some skill set addressed in the training, and ends at the post-test to verify if the employee achieved minimum necessary knowledge after the training. If the employee doesn't 
achieve minimum required score for the pre-test, the employee needs to be exposed to the watercrafts training module, in order to sell watercrafts insurance.

The R-Company was delivering the training through electronic format, as a Microsoft PowerPoint presentation, however through Adobe Captivate, where it is possible to include voice. Once the employees finished the training, they have to sign in the training portal and complete the post-test, which is again, conditioned to the minimum score: if they fail, they have to re-do the training.

For this study, we plan to accommodate the game-learning tool as an option the employee should decide about: this measure would help in capturing the interest in the game format. The target of this evaluation plan is a mix of phone sales and faceto-face sales taking watercrafts knowledge and insurance selling training. Not all participants will use the game for training, the actual number of participants may vary depends on their pre-test performances and training mode preferences. Although we can not expect how many participants we will have due to they are screening by a pretest first and the remains have option to take presentation-based training instead of game-based training, at least it is a real world project, which would show the results based on real life experience.

At the end of the process, a voluntary 6-item questionnaire as Figure 3 shows below is provided to the participants. The questionnaire is used to understand how the game was perceived by the people who chose the game, or the regular delivery format. Again, the reason of using this short questionnaire instead of 10- or 20-item questionnaire is fitting into the original on-the-job training process R-Company has, it turns out that we only have space for six items. Moreover, due to the information

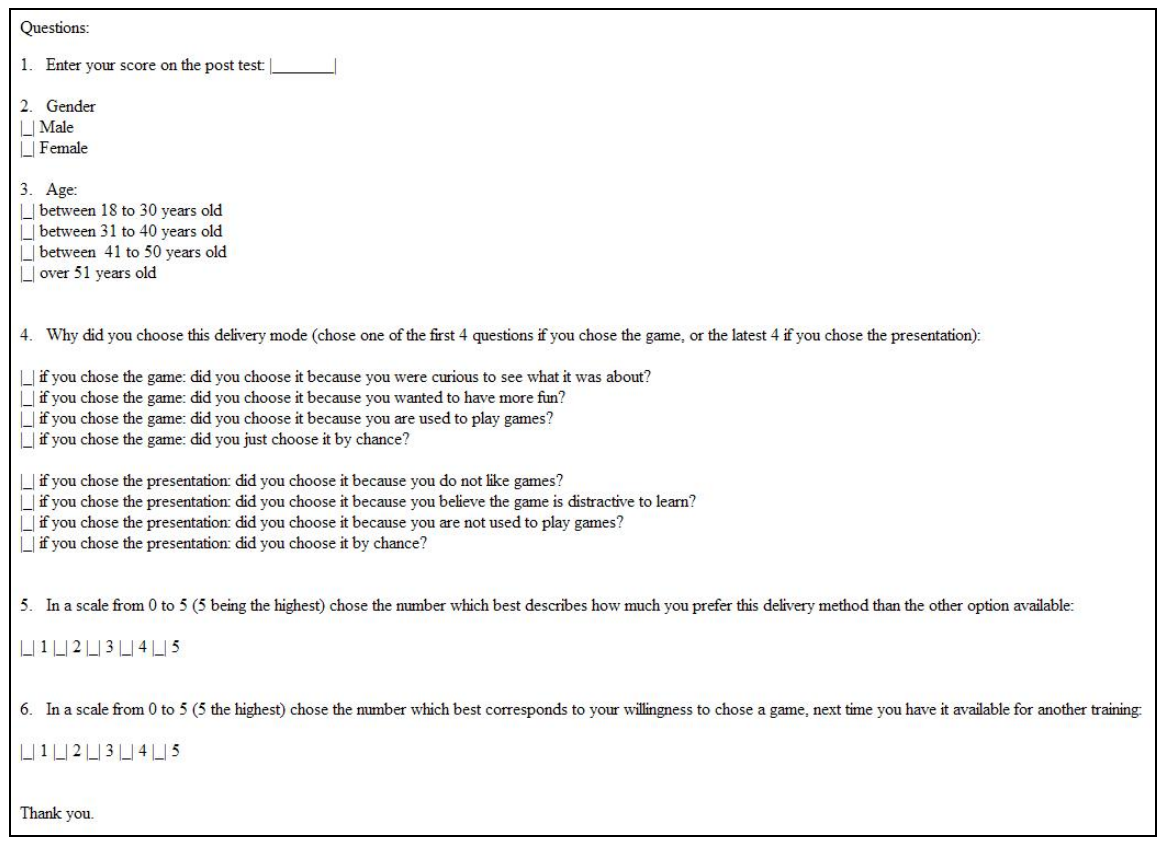

Fig. 3. The voluntary 6-item questionnaire 
privacy protection rules, the questionnaire spends four items to gather participant's personal information includes post-test score, age, gender, and training mode s/he chose. We design the remained two items to ask the participant's perception towards the game-based training mode.

\section{References}

1. Anderson, T.A.F., Reynolds, B.L., Yeh, X.P., Huang, G.Z.: Video Games in the English as a Foreign Language Classroom. In: The Proceedings of the 2nd IEEE International Conference on Digital Games and Intelligent Toys Based Education (DIGITEL 2008), Banff, Canada, November 17-19, pp. 188-192 (2008)

2. Boyle, T.: Design for multimedia learning. Prentice Hall, London (1997)

3. Cheng, H.N.-H., Deng, Y.-C., Chang, S.-B., Chan, T.-W.: Design of Multi-level Challenges of a Digital Classroom Game. In: The Proceedings of the 1st IEEE International Workshop on Digital Game and Intelligent Toy Enhanced Learning (DIGITEL 2007), Jhongli, Taiwan, March 26-28, pp. 11-18 (2007)

4. Hsiao, H.-C.: A Brief Review of Digital Games and Learning. In: The Proceedings of the 1st IEEE International Workshop on Digital Game and Intelligent Toy Enhanced Learning (DIGITEL 2007), Jhongli, Taiwan, March 26-28, pp. 124-129 (2007)

5. Shang, J., Jong, M.S.-Y., Lee, F.-L., Lee, J.H.-M.: A Pilot Study on Virtual Interactive Student-Oriented Learning Environment. In: The Proceedings of the 1st IEEE International Workshop on Digital Game and Intelligent Toy Enhanced Learning (DIGITEL 2007), Jhongli, Taiwan, March 26-28, pp. 65-72 (2007)

6. Steinman, R.A., Blastos, M.T.: A trading-card game teaching about host defence. Medical Education 36(12), 1201-1208 (2002)

7. Sung, J.-Y., Levisohn, A., Song, J.-W., Tomassetti, B., Mazalek, A.: Shadow Box: an interactive learning toy for children. In: The Proceedings of the 1st IEEE International Workshop on Digital Game and Intelligent Toy Enhanced Learning (DIGITEL 2007), Jhongli, Taiwan, March 26-28, pp. 206-208 (2007)

8. Šisler, V., Brom, C.: Designing an Educational Game: Case Study of 'Europe 2045'. In: Pan, Z., Cheok, D.A.D., Müller, W., El Rhalibi, A. (eds.) Transactions on Edutainment I. LNCS, vol. 5080, pp. 1-16. Springer, Heidelberg (2008)

9. Tan, J., Biswas, G.: Simulation-Based Game Learning Environments: Building and Sustaining a Fish Tank. In: The Proceedings of the 1st IEEE International Workshop on Digital Game and Intelligent Toy Enhanced Learning (DIGITEL 2007), Jhongli, Taiwan, March 26-28, pp. 73-80 (2007)

10. Virvou, M., Katsionis, G., Manos, K.: Combining Software Games with Education: Evaluation of its Educational Effectiveness. Educational Technology \& Society 8(2), 5465 (2005)

11. Werneck, E., Chang, M.: Where Academics Meet the Real World: Difficulties Encountered when Conducting a Project for Designing a Game-Based Learning in a Company. In: Chang, M., Kuo, R., Kinshuk, Chen, G.-D., Hirose, M. (eds.) Learning by Playing. LNCS, vol. 5670, pp. 176-183. Springer, Heidelberg (2009)

12. Wu, W.M.-C., Cheng, H.N.-H., Chiang, M.-C., Deng, Y.-C., Chou, C.-Y., Tsai, C.-C., Chan, T.-W.: AnswerMatching: A Competitive Learning Game with Uneven Chance Tactic. In: The Proceedings of the 1st IEEE International Workshop on Digital Game and Intelligent Toy Enhanced Learning (DIGITEL 2007), Jhongli, Taiwan, March 26-28, pp. 89-98 (2007) 